\title{
DISCUSSION
}

\section{Permeability and compressibility of wax-coated sands}

\author{
J.-P. BARDET*, M. JESMANI†, N. JABBARI† and S. D. N. LOURENÇO§
}

\section{Contribution by S. D. N. Lourenço}

The authors are to be congratulated for advancing the study of water-repellent soils in geotechnical engineering (Bardet et al., 2014). As mentioned, the use of waterrepellent soils offers a series of new opportunities for ground improvement, as well as contributing to elucidating the natural processes linked to these soils. However, despite their novelty to geotechnical engineering, soils coated with natural waxes have been widely studied in soil science and hydrology. The discusser has five comments, as listed below.

(a) In the schematic diagram of Fig. 1, the contact angle should refer to the wet side of the water drop. Wettable soils have contact angles of $0^{\circ}$ and water-repellent soils have contact angles $>90^{\circ}$. Super-hydrophobic surfaces are non-wettable (contact angle $\sim 180^{\circ}$ ) (Butt et al., 2006).

(b) The assumption of uniform wax coatings in Fig. 4 is questionable, in particular for the samples with reduced wax content. In naturally occurring water-repellent soils, including burned soils, it has been shown that coatings are uneven, with a patchy distribution of organic matter leading to wettable and water-repellent regions. Evidence is from particle- and field-scale studies (Dekker \& Ritsema, 2000; Cheng et al., 2009).

(c) How water repellent are the samples? Do the authors have a direct or indirect measure of this? For example, contact angles can be measured with methods from soil science such as the sessile drop method (Bachmann et al., 2000). This would assist in the interpretation of the permeability and compressibility data.

(d) How stable is the water repellency induced by the Sasolwax? Soil water repellency, as induced by natural waxes, is a very unstable condition: (i) it depends on the natural water content, (ii) it can switch from water repellent to wettable and vice-versa, and (iii) prolonged contact time with water renders the soils wettable (e.g. Doerr et al., 2000).

(e) What is the purpose of determining the saturated permeability if the soil is water repellent? It is now well accepted that naturally occurring water-repellent soils are highly impervious, such as the case of wildfire-related soils which enhance surface runoff and trigger debris flows (Moody \& Ebel, 2014). The photographs in Fig. 1 show a still water drop on top of sands coated with $1 \%$ and $6 \%$ wax, which suggests that the contact angles are $>90^{\circ}$. However, the wax-coated sands were flushed with water, presumably to overcome the water-repellent effect,

\footnotetext{
* Department of Civil Engineering, University of Texas at Arlington, Arlington, Texas, USA.

$\uparrow$ Department of Civil Engineering, Faculty of Engineering, Imam Khomeini, International University, Qazvin, Iran; Sonny Astani Department of Civil and Environmental Engineering, University of Southern California, Los Angeles, USA.

† Sonny Astani Department of Civil and Environmental Engineering, University of Southern California, Los Angeles, USA.

$\S$ Department of Civil Engineering, The University of Hong Kong, Hong Kong.
}

in order to determine the saturated permeability by falling head tests.

\section{Authors' reply}

The discusser commented upon and raised questions on the topic of (a) contact angle of water-repellent soils, (b) uniformity of wax coating, (c) degree of water repellency, (d) stability of water repellency and (e) permeability of water-repellent soils. These specific questions are best answered after sketching a background that frames the perspectives of the present study and those in soil science and hydrology.

\section{BACKGROUND}

The fields of soil science and hydrology abound with works on soil hydrophobicity in natural environments, for example, Doerr et al. (2000), Doerr \& Moody (2004) and Leighton-Boyce et al. (2007). Hydrophobic soils are water repellent; they do not wet readily under rainfall or irrigation. Infiltration and wetting can be delayed from as little as a few seconds to in excess of weeks. In natural environments, soils are understood to be hydrophobic when individual soil particles are coated by hydrophobic organic molecules, which may be released from a variety of plants, decaying organic matter, soil fauna and micro-organisms either naturally or during fires. Hydrophobicity is often noticeable after lengthy dry spells and usually disappears after extended contact with water. In the field of hydrology, soil hydrophobicity is documented to increase water runoff and soil erosion, to be distributed in uneven spatial and vertical wetting patterns, to decrease evaporation and to increase risks of groundwater pollution.

Bardet et al. (2014) carried out their study with different perspectives and objectives. They intended to create a scientific and engineering knowledge about the synthetic surfaces that have been proposed to replace natural soil surfaces in horse racing. Synthetic surfaces have raised controversies; they have been praised to be safer for horses and jockeys, but have been also intensely criticised for various reasons (Finley, 2010). They are manufactured with the intention of replicating the optimal properties of natural soils even during adverse weather conditions such as heavy rains. Unfortunately, synthetic surfaces are manufactured without much engineering by mixing empirically sandy soils with additives such as waxes, petroleum derivatives and polymers (for example, see The Blood Horse (2007) and Bardet et al. (2009)).

\section{CONTACT ANGLE}

Bardet et al. (2014) defined the contact angle $\theta$ of hydrophobic soils as shown in Fig. 15, whereas it is usually defined as $\Theta=180^{\circ}-\theta$ in soil sciences and the physics and chemistry of interfaces (e.g. Butt et al., 2003). For waxcoated sands with wax content $1 \%$ and above, they measured $\Theta$ to be larger than $90^{\circ}$; their wax-coated samples were water repellent. 


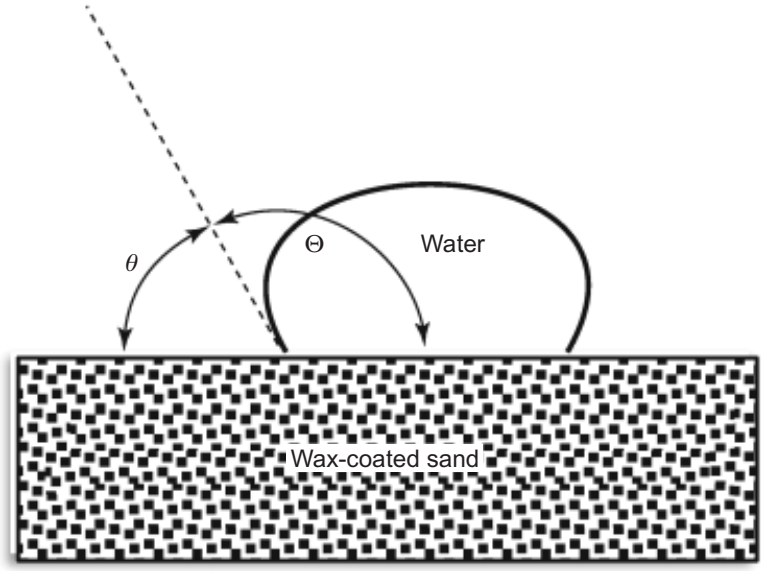

Fig. 15. The contact angle $\theta$ in Bardet et al. (2014) is related to the contact angle $\Theta$ used in the physics and chemistry of interfaces, for example, Butt et al. (2003)

\section{UNIFORMITY OF WAX COATING}

Bardet et al. (2014) manufactured wax-coated sand samples in the laboratory under controlled conditions. They heated sand that had a uniform grain size distribution on a hot plate at a temperature above the wax melting point, poured melted wax onto the hot sand and mixed the hot sand thoroughly until the melted wax gave the sand particles an even darker colour. They estimated the wax coating uniformity by visually inspecting the uniformity of the sand colour. The most uniform coatings were obtained for sands that had been washed clean of silt and clay particles. Based on this careful manufacturing, Bardet et al. (2014) calculated the average thickness of wax coating after assuming that the wax coating was uniform and the sand particles were spherical. Their main objective was to obtain an approximate thickness of wax coatings and to show that wax coatings even as thin as 0.01 to $0.04 \mathrm{~mm}$ were sufficient to influence significantly the mechanical and hydraulic properties of sands.

Bardet et al. (2014) selected a few industrial petroleum waxes for their adhesion properties. Industrial waxes are engineered to meet the demands of various applications (Krupa \& Luyt, 2000, 2001; Sasol Wax, 2014). They are used to improve the resistance of inks and coated films to rubbing, scuffing and scratching. In the corrugated board and paper industry, wax coatings prevent the transmission of moisture, microorganisms and odours. They are used for packaging food, for example, fruit, fish, meat, vegetables and sweets, as well as non-food articles. They protect various metals against corrosion, and tyres and rubbers against ultraviolet light and ozone. The construction industry utilises waxes to cure concrete surfaces evenly and enhance the insulation properties of building materials.

Compared to natural waxes and organic hydrophobic compounds, industrial and polymeric waxes have engineered properties that are designed for particular applications. It is reasonable to conclude that the wax-coated sands that are manufactured in the laboratory with engineered waxes are likely to have more stable hydrophobic coatings than naturally occurring water-repellent soils that result from highly variable environmental processes.

\section{AMOUNT OF WATER REPELLENCY}

The direct measurement of contact angles on an individual sand particle is almost impossible by conventional methods. The wax-coated sand was compressed into a flat cake to which water drops were applied. However, the contact angle was not measured precisely using the modified sessile droplet method (Bachmann et al., 2000), water droplet penetration time method (Washburn, 1921) and other methods (Yuan \& Lee, 2013). The effects of water repellency on permeability and compressibility are definitely worthy of further investigation.

\section{STABILITY OF WATER REPELLENCY}

Stability of water repellency is an issue relevant to horse racing, reminiscent of the problem that Finley (2010) reported for the Santa Anita racetrack in California. In 2007, Santa Anita replaced its one-mile course with a springy new synthetic surface, specially designed with a new microcrystalline wax that could withstand the hot temperatures in Southern California. Four months later, after the first heavy rains in December, the synthetic material had become unstable owing to drainage problems, and had transformed into a muddy field inoperable for horse racing.

The wax-coated sands that are manufactured with engineered waxes may be more stable than naturally occurring water-repellent soils, but are not without stability problems. The wax coating is beneficial when it adheres to sand grains, but has an adverse effect when it separates from sand grains, migrates downward and clogs drainage pores. Bardet et al. (2009) observed the wax saturation of drainage pores in horse-racing tracks after the wax had melted down owing to high temperatures, migrated down the track profiles and clogged the pores of lower sand layers. This wax saturation is also observed in the laboratory; wax may fill the pores of porous stones in the consolidation testing apparatus.

There is a need for additional research to improve the stability and adhesion of hydrophobic coatings on sand particles, and the durability of wax coating under repetitive loading conditions.

\section{WATER REPELLENCY AND PERMEABILITY}

A priori water repellency and permeability appear to be incompatible properties, and one could question the meaning of measuring the saturated permeability of soils that repel water. However, from another point of view, this question is surprising because synthetic surfaces have been praised for speedy drainage characteristics, allowing horse races to resume shortly after heavy rains.

Figure 16 shows the laboratory experimental set-up that Bardet et al. (2014) used to measure the permeability of waxcoated sands. The specimen is confined between two porous

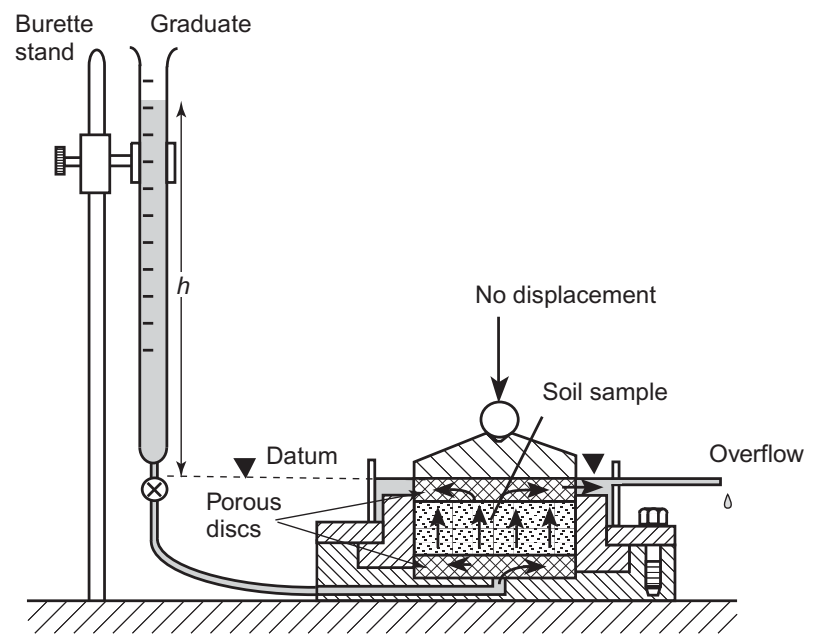

Fig. 16. Laboratory experimental set-up for measuring permeability of water-repellent soils 
stones in a fixed-ring consolidation cell (e.g. Bardet, 1997) and the upper porous stone is prevented from moving upward. At first, the burette is filled with water and its contents discharged several times through the bottom porous stone to saturate the specimen. Once the specimen is saturated, the permeability coefficient $k$ is calculated by measuring the height $h$ of the water column in the burette at several time intervals. The results obtained from this experiment, which is similar to the falling head permeability test (e.g. Bardet, 1997), were repeated multiple times and found to be reliable and consistent. The measured values of $k$ almost tripled when the wax content increased from $0 \%$ to $6 \%$.

Figure 17 shows the typical profile of a synthetic surface. The top layer that is $15-20 \mathrm{~cm}$ thick is made of wax-coated sand or similar products, and rests on top of a 5-7 cm thick layer of coarse sand that has no wax coating. A synthetic mesh lies below the sand layers on top of a $15 \mathrm{~cm}$ thick crushed stone layer with excellent drainage properties. All layers rest on an impervious membrane connected to a drainage collector system. Fig. 17 also shows the experimental set-up that was designed to measure the permeability of the top layer in the field. The field experiment consists of (a) pushing a cylindrical tube downward through the surface, (b) filling it with water and (c) measuring the time required to discharge the water column through the synthetic surface. The test estimates the time required for rainwater to infiltrate the layer. The time $t$ required for a water column of height $h$ to drain completely is

$$
t=L / k \log (1+h / L)
$$

where $k$ is the permeability of the top layer and $L$ is its thickness. For normal ranges of operation, $k$ is larger than $0.01 \mathrm{~cm} / \mathrm{s}$; it takes less than $6 \mathrm{~min}$ for $4 \mathrm{~cm}$ of water to drain through a $15 \mathrm{~cm}$ thick layer. The speedy drainage of synthetic surfaces may be counterintuitive because they are made of water-repellent materials, but field observations and laboratory experiments give similar results; permeability increases, rather than decreases with wax content and water repellency. In contrast to natural soil surfaces that may have low-permeability hydrophobic crusts (e.g. Contreras et al., 2008), synthetic surfaces have porous surfaces that are often raked to erase hoof prints and to loosen synthetic materials.

\section{CONCLUSION}

There are similarities and differences between the waterrepellent soils that are found in the natural environment and those that are manufactured with clean sands, industrial waxes, polymers and petroleum derivatives. Naturally occurring soils have hydrophobic properties that are attributed to organic substances released by plants and micro-organisms with or without the effects of fires. Natural waterrepellent soils contain fine-grained soil particles and can prevent or delay water infiltration. In contrast synthetic soils are usually made of coarser grains with a uniform grain size distribution and have engineered coatings that are more even and certainly more stable than their natural counterparts. Their inherent porosity and surrounding drainage systems make them highly permeable. Additional research at the crossroads of soil science, hydrology and geotechnical engineering is definitely warranted to explore the effects of hydrophobic coatings on soil behaviours.

\section{REFERENCES}

Bachmann, J. R., Horton, R. R., van der Ploeg, R. R. \& Woche, S. (2000). Modified sessile drop method for assessing initial soilwater contact angle of sandy soil. Soil Sci. Soc. Am. J. 64, No. 2, 564-567.

Bardet, J. P. (1997). Experimental soil mechanics. Upper Saddle River, NJ, USA: Prentice-Hall.

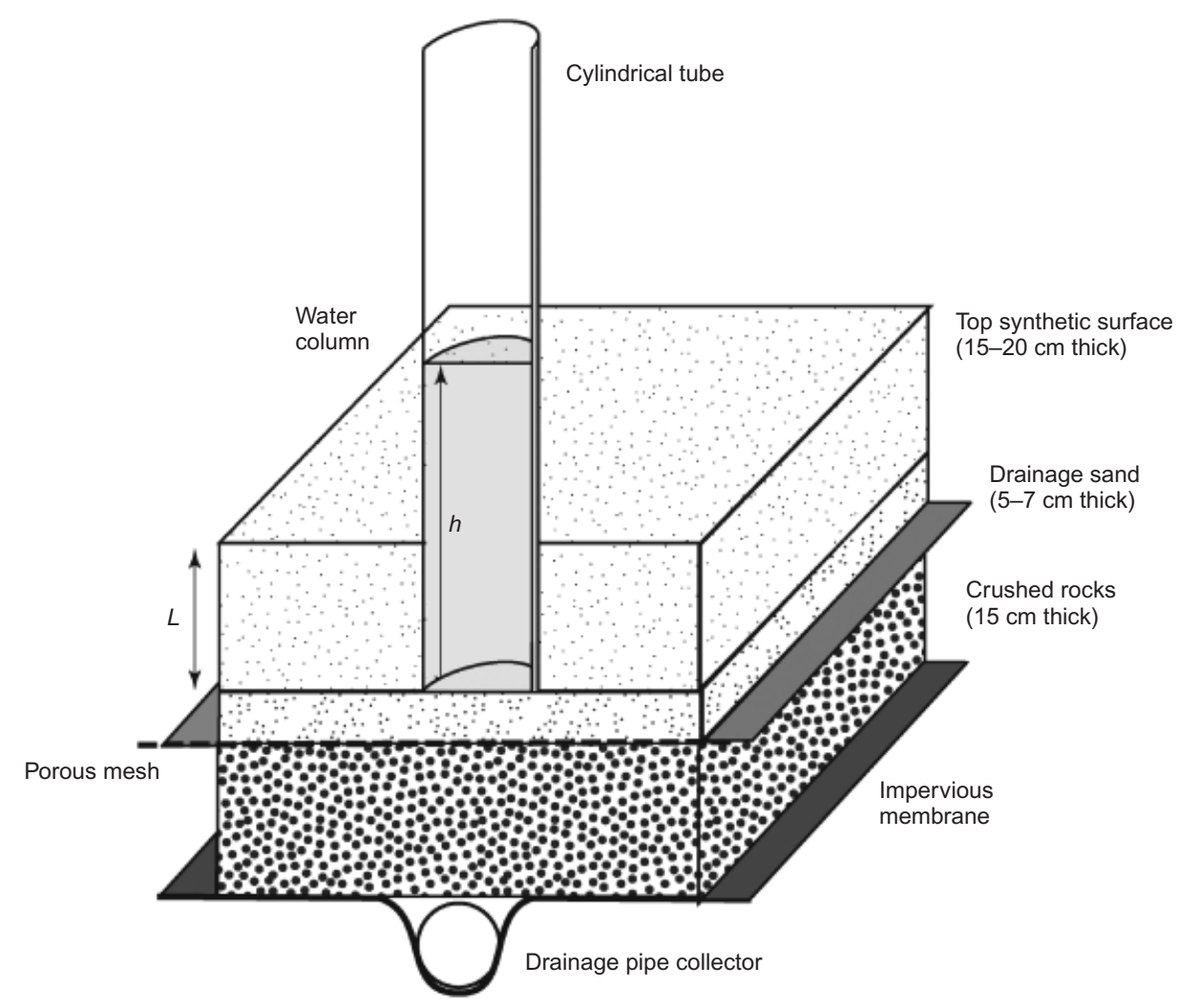

Fig. 17. Typical vertical profile of synthetic surfaces of horse-racing tracks and field test for measuring permeability of synthetic surfaces 
Bardet, J. P., Benazza, C., Bruchon, J. F. \& Mishra, M. (2009). Mechanical and hydraulic properties of wax-coated sands for sport surfaces. In Powders and grains proceedings of the 6th international conference on micromechanics of granular media (eds M. Nakagawa and S. Luding), vol. 1145, pp. 792-795. Melville, NY, USA: AIP Publishing.

Bardet, J. P., Jesmani, M. \& Jabbari, N. (2014). Permeability and compressibility of wax-coated sands. Géotechnique 64, No. 5, 341-350, http://dx.doi.org/10.1680/geot.13.P.118.

Butt, H.-J., Graf, K. \& Kappl, M. (2003). Contact angle phenomena and wetting. In Physics and chemistry of interfaces, pp. 118144. Weinheim, Germany: Wiley.

Butt, H.-J., Graf, K. \& Kappl, M. (2006). Physics and chemistry of interfaces, 2nd edn. Weinheim, Germany: Wiley.

Cheng, S., Bryant, R., Doerr, S. H., Wright, C. J. \& Williams, R. (2009). Investigation of physico-chemical surface properties of soil particles and model materials with contrasting hydrophobicity using atomic force microscopy. Environ. Sci. Technol. 43, No. 17, 6500-6506.

Contreras, S., Cantón, Y. \& Solé-Benet, A. (2008). Sieving crusts and macrofaunal activity control soil water repellency in semi arid environments: Evidences from SE Spain. Geoderma 145, No. 3-4, 252-258.

Dekker, L. W. \& Ritsema, C. J. (2000). Wetting patterns and moisture variability in water repellent Dutch soils. J. Hydrology 231, No. 232, 148-164.

Doerr, S. H. \& Moody, J. A. (2004). Hydrological effects of soil water repellency: on spatial and temporal uncertainties. Hydrol. Processes, Special Issue: Hydrogeomorphology 18, No. 4, 829-832.

Doerr, S. H. R. A., Shakesby, R. \& Walsh, P. D. (2000). Soil water repellency: its causes, characteristics and hydro-geomorphological significance. Earth Sci. Rev. 51, No. 1, 33-65.
Finley, B. (2010). Ground control, the (real) truth about synthetic surfaces. Thoroughbred Daily News (TDN) Magazine, Winter issue, see http://www.thoroughbreddailynews.com/restricted/pdf/ magazine/GroundControl.pdf (accessed 26/06/2014)

Krupa, I. \& Luyt, A. S. (2000). Thermal properties of uncrosslinked and cross-linked LLDPE/wax blends. Polymer Degradation Stability 70, No. 1, 111-117.

Krupa, I. \& Luyt, A. S. (2001). Mechanical properties of uncrosslinked and crosslinked linear low-density polyethylene/wax blends. J. Appl. Polymer Sci. 81, No. 4, 973-980.

Leighton-Boyce, G. S., Doerr, H., Shakesby, R. A. \& Walsh, R. P. D. (2007). Quantifying the impact of soil water repellency on overland flow generation and erosion: a new approach using rainfall simulation and wetting agent on in situ soil. Hydrol. Processes, Special Issue: Soil Water Repellency: Origin, Environmental Controls and Hydrological Impacts 21, No. 17, 23372345.

Moody, J. \& Ebel, B. A. (2014). Infiltration and runoff generation processes in fire-affected soils. Hydrol. Processes 28, No. 9, $3432-3453$

Sasol Wax (2014). See http://www.sasolwax.com/en/Applications. html (accessed 26/06/2014).

The Blood Horse (2007). Synthetic surfaces: special report. The Blood Horse, Special Edition: In-Depth Analysis of the New Racing Surfaces in North America 133, No. 49, 69267008 .

Washburn, E. W. (1921). The dynamics of capillary flow. Phys. Rev. 17, 273-283.

Yuan, Y. \& Lee, T. R. (2013). Contact angle and wetting properties. In Surface science techniques (eds G. Braco and B. Holst), Springer Series in Surface Sciences, pp. 3-34. Berlin/Heidelberg, Germany: Springer. 